\title{
The Development and Implementation of the Maternal Mental Health Promotion Program for Expectant Mothers
}

\author{
Mari Ikeda', Kaori Nishigaki², Miharu Kida³ , Ami Setoyama4, Kyoko Kobayashi5, \\ Kiyoko Kamibeppu ${ }^{4}$ \\ ${ }^{1}$ Nursing Administration and Advanced Clinical Nursing, Division of Health Science \& Nursing, Graduate School \\ of Medicine, The University of Tokyo, Tokyo, Japan \\ ${ }^{2}$ Pediatric Nursing, Division of Nursing, Tokyo Healthcare University, Tokyo, Japan \\ ${ }^{3}$ The University of Tokyo Hospital, Tokyo, Japan \\ ${ }^{4}$ Family Nursing, Division of Health Science \& Nursing, Graduate School of Medicine, The University of Tokyo, \\ Tokyo, Japan \\ ${ }^{5}$ Department of Child and Family Nursing, St. Luke's International University School of Nursing, Tokyo, Japan \\ Email: maritake-tky@umin.ac.jp
}

Received 4 November 2014; revised 3 December 2014; accepted 14 December 2014

Copyright (C) 2014 by authors and Scientific Research Publishing Inc.

This work is licensed under the Creative Commons Attribution International License (CC BY). http://creativecommons.org/licenses/by/4.0/

\section{(c) (i) Open Access}

\begin{abstract}
Approximately $19 \%$ of women have minor or major depression in the first three months following delivery. The Maternal Mental Health Promotion Program is an intervention program designed to deliver during pregnancy to increase awareness and limits the effects of postpartum depression (PPD). The program was developed through a literature review and a focus group interview. It has three components (information on depressive symptoms during postpartum, reflecting on pregnancy, and the importance of good communication with one's partner), delivered through lectures and group discussions using educational worksheets. The purpose of this paper was to describe the development, planning and implementing of an intervention program for expectant mothers to increase awareness and limits the effects of PPD. The program was evaluated by experienced midwives, and then delivered in antenatal classes where process evaluations were conducted. We confirmed that the objectives of the program were met and that the intervention was relevant to participants.
\end{abstract}

\section{Keywords}

Postpartum Depression, Prenatal Education, Intervention, Partner Communication 


\section{Introduction}

Postpartum depression (PPD) is a global phenomenon. Approximately 19\% of women have minor or major depression in the first three months following delivery of their child [1]. A recent large-scale epidemiological study found that the risk for depression was 1.52 times higher at postpartum than for non-pregnant/non-postpartum women [2]. In Japan, depression is experienced by approximately $20 \%$ of mothers in the first month following delivery [3].

The occurrence of PPD has been linked to several variables, including biological factors, such as a history of depression and changes in hormonal balance [4] [5]. Recently, researchers' attention has focused on psychosocial risk factors, that is, women's vulnerability to mental health problems after childbirth [6] [7]. In a comparative study, researchers found that mothers who acquired knowledge of postpartum depression in maternity classes promptly ought assistance with the emergence of the first symptoms of depression [8]. In a review by Dennis [9], several interventions had significant non-pharmacological preventative results, and one intervention included providing information on PPD during the antenatal period. In our previous study, we conducted two focus groups interviews that asked mothers' about their knowledge of PPD and whether they perceived such knowledge to be useful [10]. Those who answered that they knew about PPD believed that this knowledge was advantageous and could possibly lead to seek help in case of the possible experience of PPD.

Furthermore, mothers who had good communication with their partners regarding their anxiety felt well supported by their partners and had an image of what to expect when bringing the newborn infant home. Ogrodniczuk et al. [11] conducted a literature review on preventing postnatal depression; in their review, postpartum debriefing, continuity of care, and social support in the postpartum period were found to be important limiting the effects of PPD. The recent updated Cochrane Database of Systematic Reviews [12] of 28 trails involving almost 17,000 women, stated that overall, women who received a psychosocial or psychological intervention were significantly less likely to develop postpartum depression compared with those receiving standard care. No preventive interventions specifically targeted the mother's partner. This is a significant limitation since a lack of social support and marital conflict are strong risk factors for the development postpartum depression.

Postpartum debriefing or reflection on one's feelings may also be important for mental health because one can acknowledge immediate feelings, and then step back to reflect on them. Reflection assists one to see what goes well and focuses on the positive side of an event rather than on the more negative aspects. It is about unpacking, understanding, and constructing a response to a situation or problem, and about developing, building upon, and in some cases changing existing behaviors and practices [13].

Japanese women are advised to visit their doctor frequently during pregnancy as this provides them with many opportunities for perinatal education. In a low-risk pregnancy, prenatal visits occur every four weeks in the first 24 weeks of the pregnancy (instead of 27 weeks, as in the United States), every two weeks between 24 35 weeks gestation, and weekly after 36 weeks gestation, resulting in a total of 14 appointments [14]. In each prenatal visit, consultation with an obstetrician is followed by an appointment with a midwife. In addition to check-up visits, most maternity clinics offer maternity classes. Expectant mothers usually participate in 2 - 4 sessions, and the content varies across clinics. Some may consist of lectures by a doctor about subjects such as nutrition, while others are conducted by nurses and cover topics such as self-care during pregnancy, birth planning, or breastfeeding. Maternity classes are an excellent venue for providing the necessary information on postpartum difficulties to expectant mothers. The purpose of this paper was to describe the development, planning and implementing of an intervention program for expectant mothers to increase awareness and limits the effects of PPD.

\section{Materials and Methods}

\subsection{Development of the Maternal Mental Health Promotion Program (MMHPP)}

\subsubsection{Contents for the MMHPP}

We chose the generic cognitive vulnerability-stress model [15] as the theoretical basis for the MMHPP (Figure 1). This model presupposes that an individual with a cognitive vulnerability is more likely to become depressed than a non-vulnerable individual when confronted with a negative event and is more likely to interpret events negatively biased manner [16]. A lack of knowledge, self-reflection, and social support constitute psychosocial vulnerability for postpartum depression (Figure 2). The MMHPP has three components: 1) information on depressive symptoms in the postpartum period, 2) reflection on pregnancy, and 3) the importance of good communication 


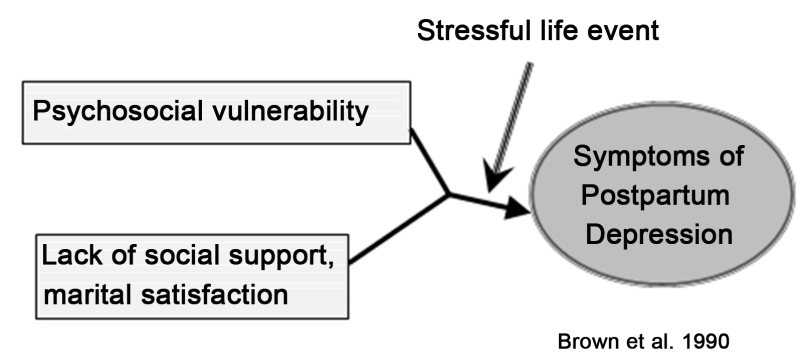

Figure 1. The cognitive vulnerability-stress model of postpartum depression.

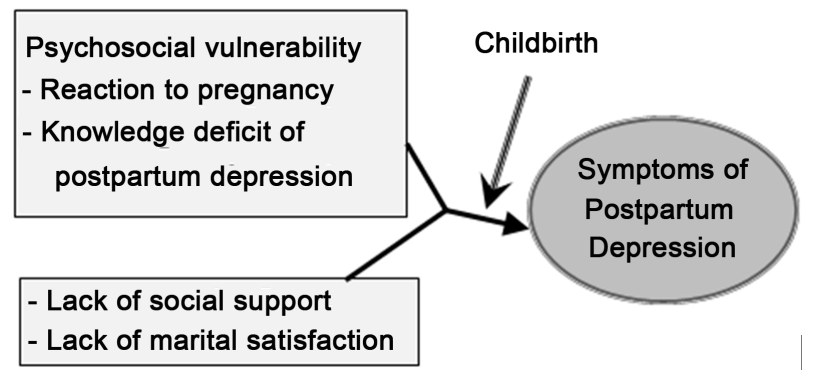

Figure 2. Conceptual model employed for the program, based on the cognitive vulnerability-stress model of postpartum depression.

with one's partner. The program consists of short lectures and working in small groups using worksheets and can be delivered in two maternity class sessions.

\subsubsection{Goal-Based Pre-Program Evaluation}

A goal-based evaluation was conducted to assess the extent to which the proposed program matched the predetermined objectives.

Participants: Those who attended the lecture of the MMHPP and gave consent to participate in the study.

Method: The midwives who conduct an antenatal education were asked to attend a lecture about the concept of the MMHPP and an overview of its contents, which included role-playing. Following this program, the first author of this study, who has experiences in qualitative research, conducted an in-depth interview with each participant separately. Three experienced midwives from the University hospital in the urban city of Japan, took part in this evaluation study. The interviewees were asked open-ended questions about the program, such as whether the three program goals-delivering information on depressive symptoms, reflecting on pregnancy, and learning the importance of good communication with one's partner-were concrete and clear. The interviews were recorded and transcribed for content analysis.

\subsection{Implementation of the Maternal Mental Health Promotion Program (MMHPP)}

\subsubsection{Contents of the MMHPP}

Using the information received from the goal-based evaluation, we created an easy-to-understand user's manual for the maternity class providers (usually midwives) that explained how to deliver the program and included worksheets to be used in the small group discussions. The worksheets included the information covered in one of the short lectures on the left side of the sheet and questions to be answered and discussed with others in the group on the right side. The program was designed to be an addition to the already existing prenatal class whereby the foremost intention was to provide mothers with increased support. The expectation was that this program will be implemented as a normal part of the prenatal classes, if the results prove to be beneficial.

In the first session, providers gave a short lecture that included information on bodily and psychological changes during pregnancy. Afterwards, participants broke into small groups and were encouraged to reflect on their thoughts regarding their pregnancy. They also identified the individuals with whom they shared such feel- 
ings and considered the activities that they have given up or have begun because of the pregnancy. Following this, the class leaders gave a lecture that emphasized the significance of partner support. This was followed by group discussions about the types of support the participants are receiving, which was intended to help participants realize that they were taking action in the interest of their own and their baby's well-being (Table 1).

In the second session, a lecture covered post-maternity blues and PPD. Participants broke into small groups and reviewed the support they received from their partners and the type of support they desired in the future. Additionally, group discussion focused on the available strategies if PPD occurred (Table 2) and participants evaluated their own vulnerability for PPD.

\subsubsection{Process Evaluation}

The MMHPP was conducted in 2013 in prenatal classes at the University Hospital in a large urban area in Japan.

1) Midwives' evaluation

Participants: The researchers recruited midwives, who were not part of the goal-based pre-program evaluation to be trained to deliver the program using the operating manuals.

Method: The MMHPP programs were delivered to mothers in prenatal classes at the University Hospital by the participants. Process evaluations are used to gain insight into how a program works. These are useful for accurately portraying a program's operation to outside parties. In this phase, we conducted in-depth individual

\section{Table 1. Content of the first session of the MMHPP.}

\begin{tabular}{|c|c|c|}
\hline Short lecture & Group discussions & Goals \\
\hline \multirow[t]{2}{*}{$\begin{array}{l}\text { Physical and psychological changes } \\
\text { during and soon after pregnancy. }\end{array}$} & $\begin{array}{l}\text { Reflect on one's pregnancy. } \\
\text { If possible, share with others. }\end{array}$ & $\begin{array}{l}\text { Taking time to reflect a few weeks away from } \\
\text { the delivery refreshes and prepares your mind. }\end{array}$ \\
\hline & $\begin{array}{l}\text { Identify those with whom you have shared } \\
\text { thoughts and worries. Is it your partner, } \\
\text { friends? Share your thoughts on the } \\
\text { relationships to and with your supporters. }\end{array}$ & $\begin{array}{c}\text { Remind yourself that you have someone } \\
\text { with whom you are very close to share } \\
\text { your anxiety or worries. }\end{array}$ \\
\hline Prenatal depression and its risk factors. & $\begin{array}{l}\text { Reflect on and discuss activities that } \\
\text { you have given up or started } \\
\text { because of pregnancy. }\end{array}$ & $\begin{array}{l}\text { Know that you are taking actions } \\
\text { (or have not yet taken action) to improve } \\
\text { your own and your baby's well-being. } \\
\text { Realize that it is quite natural to feel } \\
\text { anxious during the prenatal period. }\end{array}$ \\
\hline $\begin{array}{l}\text { The need for social support when a } \\
\text { new member arrives in the family. }\end{array}$ & $\begin{array}{l}\text { Talk about what you have so far discussed } \\
\text { with your partner regarding the delivery } \\
\text { of the child and future parenting. } \\
\text { Discuss recommendations for } \\
\text { involving partners in childrearing. }\end{array}$ & $\begin{array}{l}\text { Recognize how ready you are for } \\
\text { the childbirth, and remember that your } \\
\text { partner is your major source of support. }\end{array}$ \\
\hline
\end{tabular}

Table 2. Content of the second session of the MMHPP.

\begin{tabular}{|c|c|c|}
\hline Short lecture & Group discussion & Goals \\
\hline $\begin{array}{l}\text { Maternity blues and postpartum } \\
\text { depression. }\end{array}$ & $\begin{array}{l}\text { Discussion of postpartum depression. } \\
\text { Awareness of the disease, etc. }\end{array}$ & $\begin{array}{l}\text { Learn that two out of every ten people } \\
\text { may develop postpartum depression } \\
\text { according to previous research. }\end{array}$ \\
\hline $\begin{array}{l}\text { The risk factors of postpartum depression } \\
\text { (e.g., lack of partner's support). }\end{array}$ & $\begin{array}{l}\text { Write a list of things your partner has } \\
\text { been doing to support you since you became } \\
\text { pregnant. Share this with the group. }\end{array}$ & $\begin{array}{l}\text { Learn to share your worries and anxiety } \\
\text { with those who are in the same situation. } \\
\text { Experience the relief of sharing your } \\
\text { concerns. Rehearse help-seeking behavior } \\
\text { by discussion in small groups. }\end{array}$ \\
\hline $\begin{array}{l}\text { The significance of frequent communication } \\
\text { with your partner and good communication } \\
\text { after the birth of your child. }\end{array}$ & $\begin{array}{l}\text { Share the topics you and your partner } \\
\text { have been discussing about parenting. } \\
\text { If you have not yet been talking about } \\
\text { parenting, think about what you would } \\
\text { like to discuss with your partner. }\end{array}$ & $\begin{array}{l}\text { Realize that other people are also in the } \\
\text { process of adjusting. Get hints from } \\
\text { others who are in a similar situation. } \\
\text { Find the confidence to talk with your partner. }\end{array}$ \\
\hline $\begin{array}{l}\text { Planning a strategy in the event of } \\
\text { postpartum depression and understand the } \\
\text { importance of help-seeking behavior. }\end{array}$ & $\begin{array}{l}\text { Talk about what you would do if you } \\
\text { became depressed after the delivery. }\end{array}$ & $\begin{array}{l}\text { Identify people and places to contact for } \\
\text { help if postpartum depression occurs. }\end{array}$ \\
\hline
\end{tabular}


interviews with the four midwives who delivered the MMHPP classes. The following questions were asked in the interviews: "What do you think is required of medical staff to effectively deliver the program?" and "What do you consider to be the strengths of the program?” Each interview was recorded using an IC recorder and fully transcribed.

2) Mothers' evaluation

Participants: Mothers who attended the MMHPP during pregnancy during the study period.

Method: Twenty seven mothers who participated in the study were sent a self-report questionnaire in the mail approximately one month after the birth of their baby. The questionnaire included demographic information and a free writing section. The instructions for this section were as follows: 1) "tell us about your experience attending the prenatal class" and 2) "tell us if you talked about the contents of the program with any of your family members, and how?” The participants were asked to return the questionnaire a week after receiving it by mail. All participants returned the questionnaire and each included comments in the free writing section.

All transcripts from the interviews of the midwives in the process evaluation and the comments provided by the participants were read carefully multiple times to gain an overall understanding of the women's views and experiences and developed a coding framework. This process followed well-established procedures [17]. The goal of the procedure was to formulate categories gradually from the transcripts according to their definition and level of abstraction. Following this, the interview transcripts and comments were reviewed, and categories were tentatively developed through step-by-step deduction. Two members of the research team separately coded the transcripts; these researchers then met to discuss areas of consensus and discrepancy. Within a feedback loop consisting of three authors, the categories were revised until they had been reduced to the main categories, after which they were rechecked. We used MAXqda, a qualitative analysis software package.

\subsection{Ethical Considerations}

The study protocol was reviewed and approved by the Ethics Committee of the University of Tokyo. All participants in both the goal-oriented evaluation and process evaluation were given information stating the purpose of the study and that their confidentiality would be protected. All participants gave informed consent before the study began.

\section{Results}

\subsection{Development of the MMHPP}

The mean age of the three midwives who participated in goal-based pre-program evaluation was 35.6 years, and all had more than five years' experience in maternal nursing (Table 3). The midwives believed that providing information on PPD could limit the impact of PPD. Providing information during pregnancy was highly rated; the midwives noted that women often lack time to review and think about their own mental health after the baby is born, because they are busy with taking care of their child. The midwives were mostly positive regarding personal reflections on pregnancy. It was noted that this offers the opportunity for the mothers to express their feelings about their pregnancy, which is beneficial, particularly when the date of the delivery is near. Learning how to or continuing good communication was seen by the midwives as encouraging women to talk about their parenting style and their new roles. The three participants agreed that the program should be delivered to both parents, if possible, because involving the partner could create a safety net for the possible occurrence of PPD; the partner might suggest or arrange professional help if depressive symptoms are present, which could be difficult for the mothers to recognize or accomplish by themselves.

\subsection{Implementation of the MMHPP}

\subsubsection{Evaluation by the Midwives}

Their mean age of midwives participated in process evaluation was 31 years, and they had been working in maternal nursing for an average of 5.25 years (Table 4). Six themes surfaced during the process evaluation interviews with the midwives who led the MMHPP.

The first theme was the necessity of providing information about PPD. The midwives reported that before learning about the MMHPP, they thought that providing information on PPD would be a source of anxiety for expectant mothers. However, two of these midwives had observed PPD in their former patients and realized that 
Table 3. Participants in goal-based pre-program evaluation $(\mathrm{N}=3)$.

\begin{tabular}{cccc}
\hline Midwives & A & B & C \\
\hline Age & 41 & 39 & 27 \\
Experience of working in maternal nursing & 10 & 50 & 6 \\
\hline
\end{tabular}

Table 4. Participants in process evaluation $(\mathrm{N}=4)$.

\begin{tabular}{ccccc}
\hline Midwives & D & E & F & G \\
\hline Age & 25 & 25 & 26 & 48 \\
Experience of working in maternal nursing & 4 & 4 & 5 & 8 \\
\hline
\end{tabular}

adequate information on PPD would be helpful. The midwives were not surely aware of the prevalence of PPD; upon realizing that two out of ten women are likely to suffer from PPD, the midwives reported that mothers ought to know about PPD so that they can seek help if necessary.

If the mothers knew what PPD was, they could refer to the information they received during maternal class, even if they are affected by PPD. They can talk to their close family members. (Midwife 1)

The second theme was that this program could offer the chance to reflect on the pregnancy. Midwives thought that one message communicated in the program-reflecting on the pregnancy is done not only for the baby but also for the mother and her partner-was very important.

... to refer to your feelings toward pregnancy or review plans with your partner seems important. It may appear that it is no big deal to raise this topic, but still I feel that it's good to take time to talk, especially at this stage [before the child is born]. (Midwife 2)

The merit of the small group discussions was the third theme. The midwives observed that participants were gradually drawn into the discussion via the worksheets. Since all the participants were in approximately the same stage of pregnancy, they shared common physical problems. They also shared their worries and distress regarding communication with their partners. Some participants who were reluctant to include their partner at the delivery, but who could not refuse, received ideas from other members in the group.

The fourth theme was the merit of group intervention. Individual appointments with a midwife usually cover topics such as nutrition, exercise, and screening for infections or certain genetic diseases where appropriate. Regarding the mental health issues, this topic would only be discussed if a mother appeared to be in distress or requested an appointment or conversation about this topic. If the intervention is directed at a group, such as the maternity class, the information about PPD will be delivered to all participants; therefore, even if the participants cannot fully reveal their worries and thoughts during the group intervention, the midwives noted that the program might act as a trigger to speak out during a later, individual appointment with a midwife.

Not all mothers were able to express their feelings in the group discussion. Some were hesitant to speak up, but what I expect is that they would bring up the topic in an individual appointment with the midwife after attending the mother class. (Midwife 3)

The fifth theme was the rehearsing effect of the group discussions. Many participants gave the midwives feedback that they had talked with their partners regarding PPD. The midwives thought that talking about PPD in the group had given these participants the confidence to talk with their partners at home.

Finally, the last theme that surfaced from the interviews with the midwives was the changes in awareness among the midwives themselves. After learning and delivering the MMHPP, midwives' perception of the importance of providing information on PPD changed. All midwives revealed that they had felt uncomfortable talking about PPD for a variety of reasons. One midwife mentioned that conversations about depression might trigger symptoms if any of the women attending the maternal class had a history of depression. Other midwives said that their lack of knowledge about PPD held them back. However, with adequate information and facilitation of the small group discussions, they recognized the need to provide information about PPD in outpatient clinics to improve the awareness of the risk factors of PPD. 


\subsubsection{Evaluation by the Participants}

The second phase of the process evaluation was conducted among the participants of the program. Twentyseven women attending prenatal classes at the University Hospital participated in the MMHPP; their mean age was 34.4 (range: 26 - 39 years), and the average gestational week at the time of the intervention was 27.9 weeks (range: 25 - 35 weeks). Eleven mothers (40.7\%) were employed.

As in the first phase, six themes surfaced in the free text comments returned by the participants. The first theme was that participants were glad to know about PPD. One participant wrote that she became depressed soon after delivery, but the knowledge about PPD and sharing that information with her family helped her recover within a short period. Approximately half of the participants stated that the knowledge of PPD helped them compose themselves and react more objectively. The positive effect of reflection was the second theme. Participants noted that they evaluated their readiness for motherhood by writing and discussing in the small groups. The merit of knowing what others were doing or feeling was the third theme. Mothers found that the discussions with other mothers gave them ideas on managing their own situations. The fourth theme was the help of the program in promoting communication about PPD with their partners. Many were glad that they could talk about PPD using the worksheet and sharing correct information with their partner. Participants said that their partners tended to listen more to information from professionals and thus, their presence at the MMHPP sessions was valuable. The opportunity to talk about mental health issues with partners and family before the delivery was the fifth theme. Many participants experienced mood swings after delivery. However, because of the program and having the opportunity to talk about what may happen, they were better prepared for these abrupt changes in mood. The final theme, the importance of communicating emotions and concerns with their family and friends, was important to participants because they were able to overcome their frustration over poor communication in the partner relationship by asking advice from friends and others who had more experience in childrearing.

\section{Discussion}

The aim of this study was to describe the development, planning and implementing of an intervention program for expectant mothers to increase awareness and limits the effects of PPD. Our evaluation of the initial program indicated that the goals of the program had been achieved. Midwives who delivered the program gave generally positive evaluations. One midwife, however, mentioned that sufficient and relevant knowledge of PPD was necessary for the midwives to share and discuss this topic with mothers. This required appropriate teaching materials and easy-to-understand user's manual. The midwives noted that they had previously focused more on ensuring a safe birth than on the mother's mental health. The timing of the program during pregnancy was deemed appropriate. They also realized that women are usually fully occupied with childcare after the birth and generally do not have enough time to reflect, especially on their mental health.

The small group discussions included in the program received high evaluations for the rehearsing effect and teaching participants to seek help if necessary. Participants of the MMHPP were pleased with the small group work because they had the opportunity to share their needs and experiences with other expectant mothers [18]. Nolan et al. [19] reported that sharing and forming connections relating to pregnancy helped mothers grow in confidence as new mothers.

In our study, the participants of the MMHPP also pointed out that they were glad to know about PPD because it made them more aware of their predisposition. In the study of depression awareness program conducted by Ruble [20], those who were informed and had knowledge about depression demonstrated a significant difference in willingness to "tell someone" if concerned about depression in a peer, in contrast to a control group. Our program encouraged participants to talk with their partners and families about the possible occurrence of PPD; these conversations provided reassurance. Participants also noted that they recognized the importance of communicating with their partners. The father/partner can encourage or urge the new mother to seek help when needed.

An unexpected effect of the program was the change in midwives' perception of the importance of providing information on PPD. This effect demonstrates the potential for change in the clinical setting to include information delivery on PPD. The MMHPP made adequate information on PPD available; this might prevent women from becoming isolated due to a lack of understanding of PPD symptoms.

The present study has some limitations. First we cannot generalize the results to the larger Japanese popula- 
tion because the participants were recruited from a single University hospital with a small sample size. Also because the results were collected from the participants, the impact of the MMHPP toward partners was unknown.

\section{Conclusion}

In summary, the contents of the program-providing information on PPD so the mothers and their partners would be prepared, reflecting on pregnancy-related thoughts and sharing with women in a similar situation, and learning about the importance of communication with their partners regarding the future of their family-were all well received. Furthermore, the program also induced unexpected changes in midwives' perceptions of the importance of providing information on PPD before the delivery of the baby. This is particularly important since midwives would be the providers of further MMHPP interventions. This study reviews the development and initial presentation of the program, so we lack the quantitative data about the effectiveness of this program in limiting or preventing PPD. Future research, particularly longitudinal clinical trials, is needed to fully assess the impact of MMHPP on PPD. It may also be important to initiate classes for couples to enhance communication.

\section{Acknowledgements}

We extend our gratitude to all the expectant mothers and midwives who participated in this study. This research was supported by a Grant-in-Aid for Scientific Research (B) 21390589 from the Japanese Ministry of Education, Science, Sports and Culture.

\section{Conflict of Interest}

There is no conflict of interest to disclose.

\section{References}

[1] Gavin, N.I., Gaynes, B.N., Lohr, K.N., Meltzer-Brody, S., Gartlehner, G. and Swinson, T. (2005) Perinatal Depression: A Systematic Review of Prevalence and Incidence. Obstetrics \& Gynecology, 106, 1071-1083. http://dx.doi.org/10.1097/01.AOG.0000183597.31630.db

[2] Vesga-Lopez, O., Blanco, C., Keyes, K., Olfson, M., Grant, B.F. and Hasin, D.S. (2008) Psychiatric Disorders in Pregnant and Postpartum Women in the United States. Archives of General Psychiatry, 65, 805-815. http://dx.doi.org/10.1001/archpsyc.65.7.805

[3] Yamashita, H., Yoshida, K., Nakano, H. and Tashiro, N. (2000) Postnatal Depression in Japanese Women. Detecting the Early Onset of Postnatal Depression by Closely Monitoring the Postpartum Mood. Journal of Affective Disorders, 58, 145-154. http://dx.doi.org/10.1016/S0165-0327(99)00108-1

[4] Studd, J. and Pany, N. (2004) Hormones and Depression in Women. Climacteric, 7, 338-346. http://dx.doi.org/10.1080/13697130400012262

[5] Bloch, M., Schmidt, P.J., Danaceau, M., Murphy, J., Nieman, L. and Rubinow, D.R. (2000) Effects of Gonadal Steroids in Women with a History of Postpartum Depression. American Journal of Psychiatry, 157, 924-930. http://dx.doi.org/10.1176/appi.ajp.157.6.924

[6] Boyce, P. and Hickey, A. (2005) Psychosocial Risk Factors to Major Depression after Childbirth. Social Psychiatry and Psychiatric Epidemiology, 40, 605-612. http://dx.doi.org/10.1007/s00127-005-0931-0

[7] Milgrom, J., Gemmill, A.W., Bilszta, J.L., Hayes, B., Barnett, B., Brooks, J., Ericksen, J., Ellwood, D. and Buist, A. (2008) Antenatal Risk Factors for Postnatal Depression: A Large Prospective Study. Journal of Affective Disorders, 108, 147-157. http://dx.doi.org/10.1016/j.jad.2007.10.014

[8] Okano, T., Nagata, S., Hasegawa, M., Nomura, J. and Kumar, R. (1998) Effectiveness of Antenatal Education about Postnatal Depression: A Comparison of Two Groups of Japanese Mothers. Journal of Mental Health, 7, 191-198. http://dx.doi.org/10.1080/09638239818238

[9] Dennis, C.L.E. (2004) Preventing Postpartum Depression Part II: A Critical Review of Nonbiological Interventions. Canadian Journal of Psychiatry, 49, 526-538.

[10] Ikeda, M., Nishigaki, K. and Kamibeppu, K. (2013) A Qualitative Study of “Pregnancy Experiences” and the Meaning of Sharing It with One’s Spouse: From an Attachment Perspective. Journal of Japanese Clinical Psychology, 31, 312317.

[11] Ogrodniczuk, J.S. and Piper, W.E. (2003) Preventing Postnatal Depression: A Review of Research Findings. Harvard Review of Psychiatry, 11, 291-307. 
[12] Dennis, C.L. and Dowswell, T. (2013) Psychosocial and Psychological Interventions for Preventing Postpartum Depression. Cochrane Database of Systematic Reviews, 2, Article ID: CD001134.

[13] Claxton, G. (1999) Wise up: The Challenge of Lifelong Learning. Bloomsbury, New York.

[14] Ministry of Health, Labour and Welfare (2009) Current Situation of Prenatal Visits. Tokyo.

[15] Brown, G.W., Bifulco, A. and Andrews, B. (1990) Self-Esteem and Depression. III. Aetiological Issues. Social Psychiatry and Psychiatric Epidemiology, 25, 235-243. http://dx.doi.org/10.1007/BF00788644

[16] Bifulco, A., Brown, G.W., Moran, P., Ball, C. and Campbell, C. (1998) Predicting Depression in Women: The Role of Past and Present Vulnerability. Psychological Medicine, 28, 39-50. http://dx.doi.org/10.1017/S0033291797005953

[17] Mayring, P. (2000) Qualitative Content Analysis. Forum: Qualitative Social Research Sozialforschung [Internet]. http://www.qualitative-research.net/index.php/fqs/article/view/1089

[18] Widarsson, M., Kerstis, B., Sundquist, K., Engstrom, G. and Sarkadi, A. (2012) Support Needs of Expectant Mothers and Fathers: A Qualitative Study. Journal of Perinatal Education, 21, 36-44. http://dx.doi.org/10.1891/1058-1243.21.1.36

[19] Nolan, M.L., Mason, V., Snow, S., Messenger, W., Catling, J. and Upton, P. (2012) Making Friends at Antenatal Classes: A Qualitative Exploration of Friendship across the Transition to Motherhood. Journal of Perinatal Education, 21, 178-185. http://dx.doi.org/10.1891/1058-1243.21.3.178

[20] Ruble, A.E., Leon, P.J., Gilley-Hensley, L., Hess, S.G. and Swartz, K.L. (2013) Depression Knowledge in High School Students: Effectiveness of the Adolescent Depression Awareness Program. Journal of Affective Disorders, 150, 10251030. http://dx.doi.org/10.1016/j.jad.2013.05.033 
Scientific Research Publishing (SCIRP) is one of the largest Open Access journal publishers. It is currently publishing more than 200 open access, online, peer-reviewed journals covering a wide range of academic disciplines. SCIRP serves the worldwide academic communities and contributes to the progress and application of science with its publication.

Other selected journals from SCIRP are listed as below. Submit your manuscript to us via either submit@scirp.org or Online Submission Portal.
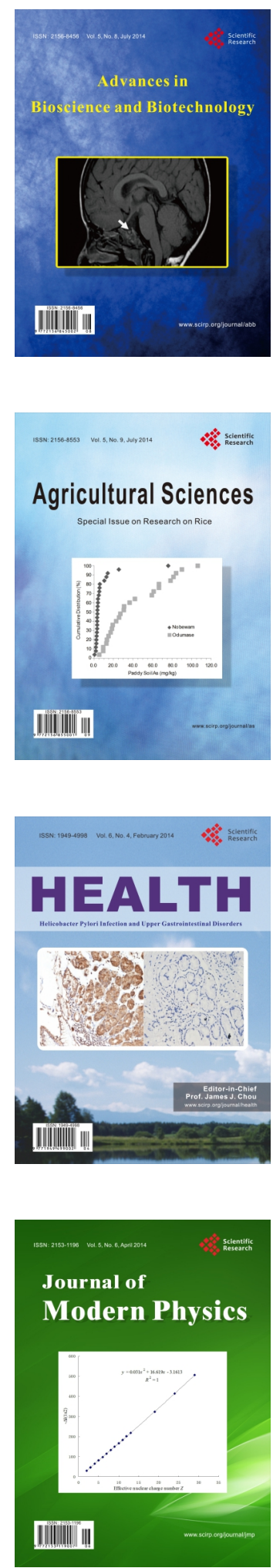
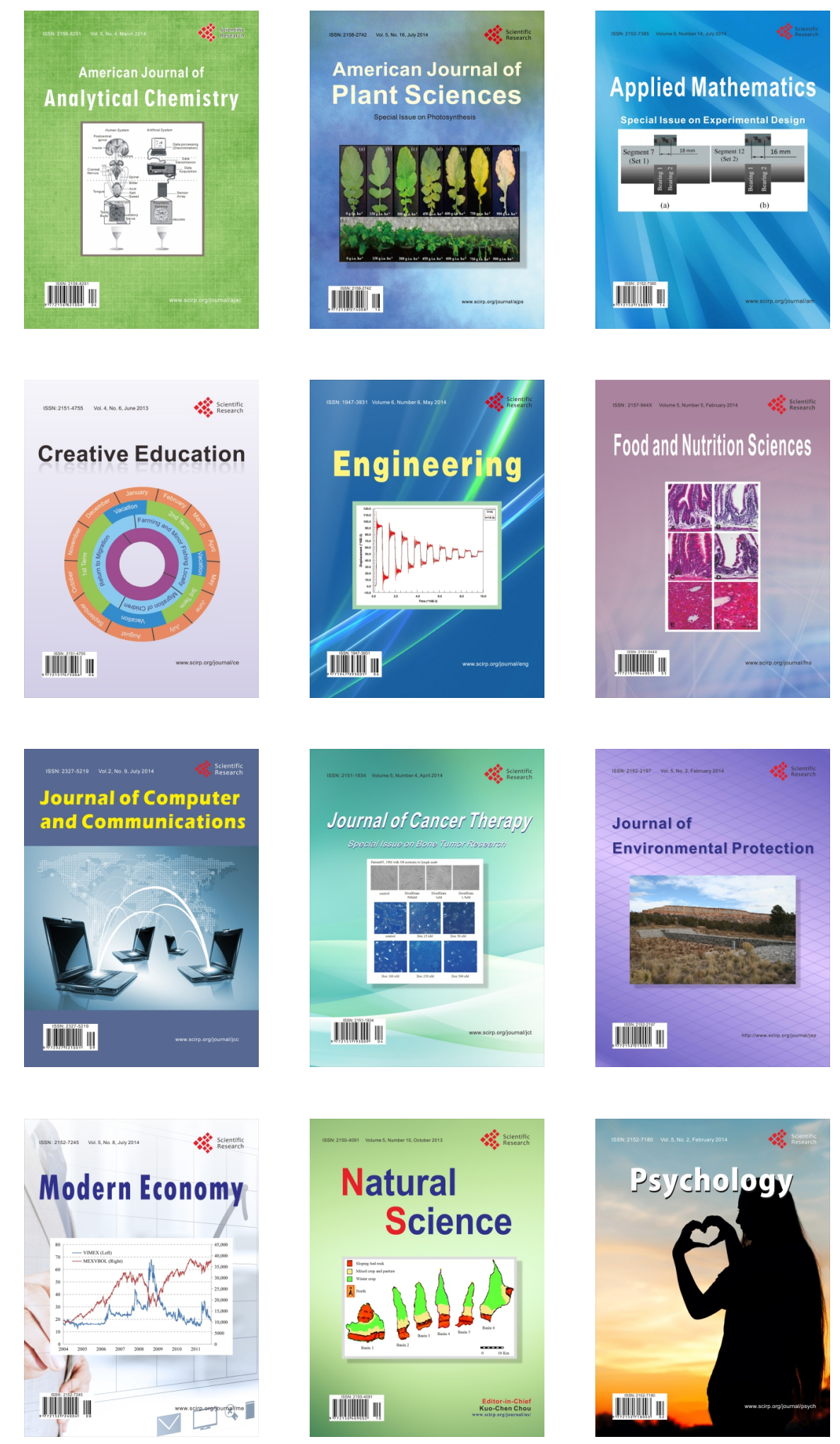